\title{
AMBIENTES EDUCATIVOS E CONHECIMENTO SOCIAL: UM ESTUDO SOBRE AS REPRESENTACְ̃̃ES DE ESCOLA
}

\author{
Eliane Giachetto Saravali* \\ Taislene Guimarães* *
}

RESUMO: Este artigo apresenta parte de uma pesquisa sobre a construção do conhecimento social fundamentada na teoria piagetiana. Os dados analisados referem-se às ideias de crianças entre 7 e 8 anos a respeito da escola. Os sujeitos foram alunos de duas classes de primeira série: uma considerada ambiente tradicional e a outra considerada ambiente sócio-moral construtivista. Os dados obtidos sofreram análise qualitativa e quantitativa e as respostas dos sujeitos foram comparadas, com a finalidade de descobrir possíveis diferenças naquilo que as crianças pensam em função do ambiente escolar do qual participam. Os resultados demonstraram que as crianças não possuem compreensão real da função da escola e que houve diferença significativa em função do ambiente escolar pesquisado, especificamente em relação à compreensão que os sujeitos apresentam das razões para a existência de uma escola e das caracterizações de uma escola boa e uma escola ruim. Dessa forma, as crianças inseridas no ambiente tradicional consideram que para a existência de uma escola é necessário somente aspectos materiais; já aquelas inseridas no ambiente sócio-moral construtivista consideram a necessidade de outros elementos, tais como as pessoas. As crianças inseridas no ambiente considerado construtivista também apontam aspectos subjetivos e referentes a comportamentos considerados adequados para a caracterização de uma boa escola, o que não ocorre com os alunos do ambiente tradicional.

Palavras-Chave: Conhecimento Social; Ambientes Educativos; Ideias sobre Escola.

\footnotetext{
* Doutora em Educação pela Universidade Estadual de Campinas (UNICAMP); Docente do Departamento de Psicologia da Educação da Universidade Estadual Paulista Júlio de Mesquita Filho (UNEP), campus de Marília-SP. E-mail: eliane.saravali@marília.unesp.br

* Pedagoga pela Universidade Estadual Paulista Júlio de Mesquita Fillho (UNESP); Docente da rede municipal de Marília-SP. E-mail: taislene_ped@yahoo.com.br
} 


\section{EDUCATIVE ENVIRONMENTS AND SOCIAL KNOWLEDGE:}

\section{A STUDY REGARDING REPRESENTATIONS ABOUT SCHOOL}

ABSTRACT: This article presents part of a research on the social construction of knowledge based on the Piagetian theory. The analyzed data refer to 7 and 8 year-old children ideas about school. The research participants were first grade students of two different classrooms from two different schools: one of the schools was considered traditional whereas the other was considered a model of socio-moral constructivism. The data have undergone qualitative and quantitative analysis and the students' answers were compared in order to discover possible differences in what those children think about the school environment in which they participate. The results showed that those children do not have a real understanding of the school's role, and significant differences were observed regarding the researched schools environment, specifically in terms of the reasons pointed by the research participants when they were asked to justify the existence of a school and to set which would be the main aspects of a good and a bad school. Thus, the children who were included in the traditional context considered that the existence of a school is connected with material aspects only, on the other hand, those who were included in the socio-moral constructivist context considered the need of other factors, such as people. The children involved in the constructive environment have also elected subjective aspects that, from their points of view, were related to what they considered appropriate behavior for the characterization of a good school, which did not occur with students from the traditional environment.

Keywords: Social Knowledge; Educational Settings; Ideas about School.

\section{Introdução}

Ao pensarmos em ações docentes em sala de aula, tais como a organização do trabalho pedagógico, o planejamento e a execução de atividades, a tomada de decisão em relação à maneira de se abordar determinado conteúdo, não deveríamos deixar de pensar ou de fundamentar nossas escolhas em informações sobre o desenvolvimento e a aprendizagem de nosso aluno. Conhecer esses processos permite maior fundamentação para nossa ação e o direcionamento do trabalho em bases científicas, e não apenas de senso comum.

O epistemólogo suíço Jean Piaget (1896-1980), mesmo sem a intenção prévia de pensar em questões pedagógicas, deixou enorme legado nesse sentido, uma vez que explicou e demonstrou, em inúmeros trabalhos, como compreendemos, avançamos e construímos diferentes noções e conceitos acerca da realidade física e social. 
No presente artigo, buscamos apresentar os resultados de uma pesquisa ${ }^{1}$ que investigou a construção do conhecimento social, sob a ótica da teoria piagetiana, em crianças de 7 e 8 anos, especificamente as ideias dessas crianças sobre a escola, em ambientes educacionais diferenciados.

Pretendemos mostrar que as crianças percorrem caminhos bastante singulares na construção desse tipo de conhecimento e que nossas ações em sala de aula podem favorecer ou não a consolidação e o sucesso dessas construções.

\section{0 conhecimento social na perspectiva piagetiana}

Desde muito jovem, Piaget mostrou-se interessado na observação de fenômenos naturais. Estudou filosofia, lógica e religião, ainda na adolescência, interessando-se pela epistemologia.

Formado em Biologia, deixou inúmeras contribuições de pesquisas apoiadas no método clínico-crítico, usado em observações e entrevistas. Tais pesquisas revelam como as crianças nos fornecem informações acerca de seu desenvolvimento, seja quando indagam seja quando respondem às nossas indagações. Seus trabalhos, reconhecidos mundialmente entre psicólogos, filósofos e educadores, estimulam o diálogo a propósito de experiências que provocam o pensamento e desafiam a inteligência.

As pesquisas piagetianas trazem contribuições significativas no âmbito da construção do conhecimento, ultrapassando as barreiras das teorias, ideias ou deduções, fazendo suas comprovações a partir de experiências práticas com a realidade, sempre apoiadas no método clínicocrítico. O escopo de seu trabalho foi evidenciar o longo processo de construção por equilibração que percorremos no aperfeiçoamento de nossas capacidades adaptativas. Sobre essa construção, Piaget demonstrou que se poderia traçar um paralelo entre as concepções empiristas e inatistas. Segundo seu pensamento, o conhecimento não consiste numa simples cópia da realidade ou num simples desdobramento de estruturas pré-formadas; ao contrário:

(...) o conhecimento não procede, em suas origens, nem de um sujeito consciente de si mesmo nem de objetos já constituídos (do ponto de vista do sujeito) que a ele se imporiam. O conhecimento resultaria de interações que 
se produzem a meio caminho entre os dois, dependendo, portanto, dos dois ao mesmo tempo, mas em decorrência de uma indiferenciação completa e não de intercâmbio entre formas distintas. (PIAGET, 1978, p. 6)

Os estudos de Piaget, como também os de seus seguidores, demonstraram que nem todos os conhecimentos são da mesma natureza. Portanto, de acordo com o referencial piagetiano, há três tipos de conhecimento: o físico, o lógico-matemático e o social.

Simplificadamente, podemos dizer que o conhecimento físico é aquele adquirido a partir da experiência direta sobre os objetos, pelo processo de descoberta e estruturado a partir da "abstração empírica", isto é, a "abstração das propriedades observáveis que são inerentes aos objetos" (ASSIS, 2003, p. 78). Cor, forma, textura, gosto, odor, entre outros, são alguns exemplos de propriedades que encontramos nos objetos.

O conhecimento lógico-matemático é aquele estruturado a partir da "abstração reflexionante" que tem origem nas coordenações internas realizadas a partir das ações que os indivíduos exercem sobre os objetos. Por meio da abstração reflexionante são criadas e introduzidas relações entre os objetos, através, por exemplo, de comparação e de quantificação.

O conhecimento social é o conhecimento proveniente das transmissões sociais, fruto das determinações e interações sociais. Tal conhecimento é adquirido a partir de informações fornecidas pelas pessoas e pelo ambiente social em que estão inseridas.

Kamii (1996), em muitos dos seus estudos, demonstra as peculiaridades da natureza do conhecimento expressas por Piaget, principalmente tratando-se do conhecimento lógico-matemático. Num de seus escritos, ela distingue conhecimento físico de conhecimento lógicomatemático, exemplificando:

O fato de que uma bola rola em uma rampa, que uma certa combinação de materiais produz cristais e que certos objetos flutuam na água é um exemplo de conhecimento físico. A fonte do conhecimento físico está, portanto, principalmente no objeto, ou seja, na forma com que o objeto proporciona ao sujeito oportunidades para observação. O conhecimento lógicomatemático, por outro lado, consiste nas relações que o sujeito cria e introduz nos, ou entre objetos. Um exemplo de conhecimento lógico-matemático é o fato de que, no exercício de inclusão da classe, existem mais cubos que cubos azuis. [os cubos] não estão organizados dentro da classe de "todos os cubos" 
compostos das subclasses "cubos amarelos" e "cubos azuis" até que a criança crie essa organização hierárquica e introduza-a entre os objetos. (KAMII; DEVRIES, 1991, p. 32-33).

Em relação ao conhecimento social, a autora acredita que sua origem principal esteja nas convenções construídas pelas pessoas, a característica principal desse tipo de conhecimento seria a arbitrariedade.

É importante salientar que além dos escritos de Kamii, muitos pesquisadores avançaram em relação à natureza dos conhecimentos e às peculiaridades do conhecimento social, não o entendendo como um conhecimento construído por simples transmissão, mas como uma construção individual e constante do sujeito. $\mathrm{Na}$ verdade, os resultados das pesquisas sobre o conhecimento social corroboram aquilo que a teoria piagetiana acredita ser o papel ativo do sujeito que conhece.

Para Piaget, o desenvolvimento psicológico, que conduz a criança ao pensamento adulto, "não dependeria unicamente de fatores psico-biológicos hereditários, nem simplesmente da pressão do meio físico sobre o espírito, mas, sobretudo, da influência da vida social sobre o indivíduo" (PIAGET, 1998, p. 12). Nessa perspectiva, a construção do conhecimento social vai assumir uma interpretação diferente, a de que os dados não se impõem, mas são reorganizados, interpretados, o que condiz com os processos de assimilação e acomodação ${ }^{2}$. Portanto, as crianças transformam os fenômenos sociais em objetos de conhecimento, transformando suas ideias bastante singulares em conceitos.

Muitos pesquisadores têm se dedicado a investigar e explicar como se dá a construção desse tipo de conhecimento na perspectiva piagetiana. Entre eles podemos destacar os estudos espanhóis de Delval (1988; 1992) e Enesco et al. (1995), e o de seus colaboradores, destacando-se os trabalhos realizados no Chile por Denegri (1998). No Brasil, temos já a configuração de vários grupos de pesquisa e estudos nessa linha, destacando-se os desenvolvidos, a partir de 1993, pelo Laboratório de Psicologia Genética da Faculdade de Educação da Unicamp (ASSIS, 2003).

Segundo esses pesquisadores, durante o desenvolvimento infantil, a criança vai formando representações dos diferentes aspectos da sociedade em que vive, sendo essa representação produto da influência dos adultos e "resultado de uma atividade construtiva a partir de elementos fragmentados que recebe e seleciona" (DELVAL, 1989, p. 
245). Dessa forma, podemos concluir que a criança realiza uma tarefa individual que nada tem a ver com uma assimilação passiva.

Enesco et al. (1995) esclarecem que, ao se tratar do conhecimento social como objeto de conhecimento, estuda-se aquilo que é produzido em um contexto social e que adquire seu significado no seio das relações com os outros. Esse objeto de conhecimento pode se caracterizar por diferentes dimensões, tais como: o conhecimento do eu e dos outros (conhecimento psicológico ou pessoal), as relações interpessoais, os papéis sociais, as normas que regulam as condutas dentro do grupo social, o funcionamento e a organização da sociedade (econômico, político, etc.).

Ao considerarmos essas diferentes dimensões que compõem o conhecimento social, observamos que as crianças sofrem múltiplas influências sociais por meio de interações entre elas e tudo e todos que fazem parte do ambiente em que estão inseridas, como, por exemplo: a linguagem, os valores, as regras e normas sociais do grupo, o exercício dos papéis, etc. É a partir dessas trocas e, sobretudo, da qualidade dessas trocas que as crianças iniciam a construção de suas representações da realidade social. Enesco e Navarro completam essa ideia: "Esto no significa que los niños inventen la realidad a espaldas de ella, pero si que construyen representaciones que no son copias de ella, sino inferências realizadas a partir de aquelas interacciones u observaciones que, utilizando la terminologia piagetiana, pueden asimilar" (ENESCO; NAVARRO, 1994, p. 72).

Uma prova de que o conhecimento social é construído é a de que as crianças desenvolvem ideias ou explicações que não foram "transmitidas" ou "ensinadas" diretamente pelos adultos. Num de seus inúmeros trabalhos, Delval (1990) conta que se surpreendeu a primeira vez que uma criança de 9 anos lhe disse que as pessoas eram pobres porque "não tinham dinheiro para comprar trabalho", e continuou a surpreender-se quando percebeu que as crianças da mesma idade de diferentes países e níveis sociais davam respostas semelhantes, dando-lhes caráter universal. Tais respostas não revelavam uma prática comum na sociedade, tampouco algo que era ensinado às crianças. Nesse sentido, Denegri explica que:

(...) a criança constrói uma representação da organização social a partir dos elementos que são proporcionados pelos adultos, os meios de comunicação de massa, as conversas, as informações que recebe na escola e suas próprias 
observações. No entanto, ainda que esteja imersa no mundo social desde que nasce, sua experiência é peculiar e distinta do adulto. Em primeiro lugar, tratase de uma experiência muito mais reduzida que a do adulto, e, além disso, fragmentada. Há muitas coisas e lugares aos quais não têm acesso, não participa da vida política e - ainda que esteja submetida a múltiplas restrições por parte dos adultos - ignora os deveres e direitos e como é exercida a coação e a participação social. Por outro lado, a insuficiência de seus instrumentos intelectuais ainda em desenvolvimento, a impedem de organizar as informações que recebe e articulá-las em um sistema coerente. Assim, chega a conformar conceitualizações próprias ou teorias implícitas que são divergentes das adultas e que, curiosamente, mostram grande semelhança entre crianças de diferentes países e meios sociais. (DENEGRI, 1998, p. 45)

Essas conceituações próprias que revelam as crenças espontâneas que as crianças vão elaborando acerca da realidade social foram encontradas em diversas pesquisas como as de Delval (1988; 1989; 1992; 1993), Enesco (1996), Denegri (1998).

Nesses diferentes trabalhos de investigação, é possível encontrar concepções infantis referentes a várias noções do conhecimento social, entre eles podemos destacar: as pesquisas de Sierra e Enesco (1993), que realizaram um estudo evolutivo a respeito da compreensão que as crianças possuíam sobre o acesso a distintas profissões; os estudos de Delval e Echeita (1991) e Delval (2002), que buscaram conhecer a compreensão que crianças tinham em relação ao mecanismo de intercâmbio econômico (compra e venda) e ao lucro; o trabalho de Enesco et al. (1995), que investigaram as mudanças evolutivas na representação do funcionamento da sociedade, assim como na compreensão dos elementos que compõem a organização social (riqueza e pobreza, estratificação e mobilidade social, as explicações sobre desigualdade em grupos sociais diferentes, etc.). A respeito desse último trabalho, vale dizer que Denegri (1998) e Navarro e Peñaranda (1998) encontraram resultados semelhantes aos de Enesco et al. (1995), ao trabalharem com crianças chilenas e mexicanas.

No contexto brasileiro, destacamos os trabalhos de Tortella (1996; 2001), que observou a evolução das representações das crianças sobre a amizade; a pesquisa de Godoy (1996), que investigou as ideias infantis sobre etnia; o trabalho de Saravali (1999) a respeito da evolução do conceito de direito e o estudo de Borges (2001) sobre o conceito de família.

Os resultados dessas pesquisas nos auxiliam a compreender a construção do conhecimento social, mostrando, em relação a diferentes 
conceitos e noções, como as crianças dão sentido à realidade. Os estudos referentes à construção desse tipo de conhecimento explicam processos e concepções peculiares que os sujeitos têm e vão construindo sobre a realidade social que os cerca.

Tais resultados são bastante significativos não somente para aqueles que se dedicam ao estudo da epistemologia ou da psicologia, mas também para os que lidam com a pedagogia.

Dessa forma, os professores necessitam conhecer os processos percorridos por seus alunos a fim de organizarem as situações didáticas que caminhem ao encontro desses processos. A esse respeito, Delval (1993) afirma que quando a escola negligencia essa construção realizada pelo indivíduo, corre um grande risco de estabelecer dois conhecimentos independentes na mente do aluno: aquele formado pelas ideias e experiências individuais que cada um busca na tentativa de uma melhor compreensão do mundo que o cerca e um outro formado pelas informações provenientes do ambiente escolar, que são memorizadas e repetidas nas provas e exames. Esses sistemas podem permanecer separados, sem que o sujeito consiga estabelecer relação entre eles.

Compreender os resultados e o significado dessas pesquisas à luz da teoria piagetiana e da construção do conhecimento social significa, na situação escolar, refletir com cuidado antes de se fazer escolhas sobre o trabalho com determinado conteúdo. Ou seja, é fundamental compreender que a simples transmissão de uma informação é sempre interpretada pelo sujeito que a recebe, no caso o aluno, que elabora e reelabora suas representações, dando um sentido próprio a esses conteúdos e transmissões. Nesse sentido, antes mesmo de se pensar em atividades ou procedimentos didáticos para o trabalho de um ou outro conteúdo, é importante conhecer como se dá, para os alunos, a gênese das noções que se quer trabalhar, de tal forma que o trabalho respeite, considere e vá ao encontro dos processos percorridos pelas crianças. 


\section{As ideias das crianças sobre a escola e o papel dos ambientes educativos}

Entre as pesquisas realizadas no campo da construção do conhecimento social são escassas as que dizem respeito às ideias das crianças acerca da realidade escolar. Os poucos trabalhos existentes voltados à compreensão do raciocínio infantil envolvido na construção desse tipo de conhecimento social mostraram o quanto se faz importante um estudo dessa natureza para a compreensão de diversos aspectos do desenvolvimento infantil, uma vez que a caracterização dessas ideias acaba por refletir na disposição para a aprendizagem, como já discutiu Cruz (1987) em sua pesquisa.

No Brasil, destacamos os estudos de Cantelli (2000), Cruz (1987), Chaves e Barbosa (1998) e Gonçalves (1990) referentes ao conhecimento da escola e de seu papel social.

O trabalho de Cantelli (2000) apresenta um estudo evolutivo das representações sobre a escola em crianças e adolescentes. Os resultados obtidos indicaram a existência de uma evolução nas representações sobre a noção de escola.

O estudo de Cruz (1987) investigou a evolução da representação de escola num grupo de cinco crianças pobres trabalhadoras durante seu primeiro ano de escolaridade. A partir dos resultados constatou-se que a representação de escola nesse grupo de crianças evoluiu negativamente, isto é, ao final do ano elas passaram a ver a escola como um ambiente desinteressante e destinado a poucos.

Chaves e Barbosa (1998) buscaram identificar as representações sociais de crianças acerca da sua realidade escolar. Seus resultados mostraram que as famílias, mesmo das crianças pobres, apresentaram grande interesse e empenho para com a escolarização de seus filhos, contradizendo pesquisas anteriores que apontavam negligências e desleixos destas em muitas situações. As crianças também apresentaram uma representação positiva da escola, valorizando-a e valorizando o professor que se relaciona bem, que conversa e que é afetuoso.

Gonçalves (1990) buscou conhecer a representação da escola feita por crianças de baixa renda em sua primeira experiência discente. Ela percebeu que a desvalorização da criança enquanto sujeito ativo do processo de construção do conhecimento e a intenção de adaptá-la à escola e ao mundo social fazem com que não exista uma real visão do papel da escola. 
Todos esses trabalhos, na mesma direção de outras pesquisas referentes a diferentes noções do conhecimento social, também mostram a importância de se conhecer o que as crianças pensam, que ideias possuem sobre um conceito, bem como estar sempre atento ao fato de que os sujeitos não fazem assimilações passivas da realidade, como já comentamos anteriormente. Além do mais, ao ouvir o que pensam as crianças, podemos obter informações preciosas sobre seus sentimentos, percepções e concepções que muito podem auxiliar no processo de interação entre educador e aluno, sobretudo quando se trata das crenças dos pequenos sobre a escola e sobre o professor.

A partir dessa análise teórica e considerando as contribuições dos diferentes estudos e pesquisas na linha do conhecimento social é que a presente pesquisa foi pensada. Buscou-se compreender as noções que crianças da primeira série teriam sobre a escola e sobre o professor ${ }^{3}$. Todavia, no presente estudo, buscamos também analisar a influência que um ambiente educacional pode ter em relação à construção do conhecimento social.

Acreditamos que a maneira como o ambiente é organizado, incluindo, principalmente, o planejamento e o oferecimento de atividades em função dos processos de desenvolvimento e aprendizagem discentes, tem influência sobre a maneira como os alunos vão construindo suas representações da realidade social. Dessa forma, buscamos observar e comparar a construção das ideias sobre a escola e sobre o professor em dois ambientes de ensino: um ambiente tradicional e um ambiente considerado sócio-moral construtivista.

Para ambiente sócio-moral construtivista adotamos a definição de Devries e Zan (1998). De acordo com essas autoras, trata-se de um ambiente permeado por uma relação horizontal entre professor e aluno, respeito mútuo e relações de cooperação; o professor construtivista "coopera com as crianças, as estimula a apresentarem ideias sobre o que aprender e facilita a exploração, experimentação, investigação e invenção” (DEVRIES; ZAN, 1998, p. 79).

Araújo (1996) apresenta a definição desse tipo de ambiente denominando-o de ambiente cooperativo:

(...) nele a opressão do adulto é reduzida o máximo possível, e nele encontram-se as condições que engendram a cooperação, o respeito mútuo, as atividades grupais que favorecem a reciprocidade, a ausência de sanções 
expiatórias e de recompensas, e onde as crianças têm oportunidade constante de fazer escolhas, tomar decisões e de expressar-se livremente. (ARAÚJO, 1996, p. 111)

Esse autor destaca ainda que, em condições como essas, a criança tende a libertar-se do egocentrismo, da submissão cega e do respeito unilateral, adentrando ao desenvolvimento intelectual e moral mais avançados.

Em contraposição a esse tipo de ambiente, há o ambiente de ensino denominado tradicional, no qual muitas vezes a superioridade do adulto inibe a discussão e a cooperação que deveriam ocorrer entre os alunos. Nesse ambiente, o ensino é totalmente centrado no professor, as possibilidades de ação por parte dos educandos são mínimas, bem como as oportunidades de questionamentos, reflexões, erros e explorações. Devries e Zan (1998) definem esse ambiente como um local de absoluto controle: há imposições de conteúdo, evita-se constantemente a ocorrência de conflitos e debates e as necessidades emocionais e físicas dos alunos não são consideradas.

Embora quando se trate das definições de ambientes educativos e suas caracterizações haja uma ênfase em questões voltadas ao desenvolvimento moral e à indisciplina, não podemos deixar de pensar que as influências proporcionadas por esses ambientes ocorrem em todos os aspectos do desenvolvimento infantil. $\mathrm{Na}$ verdade, as definições e caracterizações desses ambientes caminham no sentido exposto por Piaget (1998), que diferenciou os métodos ativos daqueles receptivos ou de ênfase exclusiva na transmissão pelos mestres.

As pesquisas de Saravali (1999) e Borges (2001) mostraram que num ambiente sócio- moral construtivista ou cooperativo mesmo crianças bem pequenas, da educação infantil, podem avançar na construção do conhecimento social a partir de um trabalho destinado a esse fim.

Considerando-se essas importantes questões que caracterizam diferentes formas de se organizar um ambiente escolar e, consequentemente, de promover o desenvolvimento infantil, a presente pesquisa foi delineada. Será que alunos que participam de um ambiente cooperativo, onde as discussões, as trocas e os erros são valorizados, teriam maiores chances de debater e pensar sobre as questões que envolvem o conhecimento social? Consequentemente, será que esses alunos teriam concepções diferentes a respeito dos aspectos da realidade social, no caso do que 
trazemos para o presente artigo, da escola, do que aqueles alunos que pertencem a ambientes mais tradicionais? A seguir passaremos a apresentar nossa pesquisa.

\section{A pesquisa}

O objetivo geral do nosso trabalho era comparar as representações de escola e de professor ${ }^{4}$ de crianças inseridas num ambiente educacional sócio-moral construtivista com as de crianças inseridas num ambiente educacional tradicional. Para tanto, trabalhamos com 52 sujeitos entre 7 e 8 anos: 30 alunos regularmente matriculados numa primeira série considerada um ambiente tradicional e 22 alunos regularmente matriculados numa primeira série considerada um ambiente sócio-moral construtivista.

A seleção dessas salas foi feita no município de Marília-SP, a partir do contato estabelecido pelo pesquisador com diferentes docentes e a realização de visitas às salas de aula.

O critério utilizado para a seleção das salas foi o da predominância de características que evidenciassem um ou outro tipo de ambiente educacional. $\mathrm{O}$ ambiente tradicional escolhido apresentou relações coercitivas, autoritarismo da professora, expiação, rigidez e, muitas vezes, agressão à autoestima dos alunos. Já o ambiente sócio-moral construtivista apresentou uma postura docente diferenciada, com a existência de discussão prévia das atividades a serem desenvolvidas, rodas de conversas, sistema de votação para tomada de decisões, momentos de construções coletivas de textos, trabalho em duplas e resolução de conflitos de indisciplina sempre por meio de conversas.

A sala correspondente ao ambiente tradicional pertencia a uma escola municipal que estava localizada num bairro periférico da cidade e atendia a uma população de classe baixa. O horário de funcionamento da escola correspondia ao período diurno e a sala escolhida para fazer parte da pesquisa funcionava no período vespertino.

A sala correspondente ao ambiente sócio-moral construtivista estava numa escola estadual, também localizada num bairro periférico com população predominantemente de classe baixa. A escola também atendia somente no período diurno e a sala eleita funcionava pela manhã. 
As professoras das duas salas eram formadas em Pedagogia.

Apesar das características semelhantes, para a análise e o tratamento de nossos dados consideramos apenas a variável "ambiente educativo", ou seja, sala de aula tradicional ou cooperativa.

Em ambas as salas foram entregues Termos de Consentimento Livre e Esclarecido a fim de obtermos autorização dos responsáveis para os alunos participarem da pesquisa. Foram entregues também pedidos de autorização para as professoras responsáveis pelas salas e para os diretores das escolas, que receberam também uma cópia completa do projeto a ser realizado em suas respectivas instituições.

Os instrumentos metodológicos utilizados foram construídos e testados num estudo-piloto, também realizado em Marília-SP, e são compostos por uma entrevista semiestruturada, uma história envolvendo uma situação-problema de sala de aula e uma proposta de desenho. Em razão dos limites deste artigo, apresentaremos somente os dados obtidos na entrevista semiestruturada e que dizem respeito às representações sobre escola.

A coleta de dados ocorreu entre os meses de outubro e dezembro de 2006, de modo que as crianças tiveram a oportunidade de conviver em seus respectivos ambientes escolares por um período de aproximadamente um ano letivo.

No momento da coleta, cada criança era convidada individualmente a se retirar da sala de aula e a se dirigir a outra sala destinada à realização da pesquisa. A criança permanecia nesse local com o experimentador entre vinte e quarenta minutos ou até que terminasse a aplicação dos três instrumentos, que seguiam sempre a mesma sequência: aplicação da entrevista, análise da história e realização do desenho.

As questões que compuseram a entrevista foram as seguintes:

1- Você acredita ser importante frequentar a escola? Por quê?

2- O que você faz na escola? Isso serve para quê?

3- Qual o momento do dia (rotina escolar) de que você mais gosta? E o de que menos gosta?

4- O que é preciso para ser uma escola? Por que é necessário tudo isso?

5- Para você, o que é uma escola boa? E uma escola ruim?

6- Para você, o que um professor faz? Para que serve um professor?

7- Qualquer pessoa pode ser professor? Como a pessoa aprende a ser professor?

8- Para você, o que seria um "bom" professor? E um "mau" professor?

9- Como se deve ensinar? 
Essas entrevistas foram gravadas e, posteriormente, transcritas para análise.

\section{Os resultados da entrevista}

A análise dos dados tomou por referência os mesmos procedimentos adotados em outras pesquisas sobre a construção do conhecimento social (DELVAL, 2002), bem como estudos específicos sobre a escola e o professor, como o trabalho de Cantelli (2000).

Delval (2002) ressalta que, em estudos dessa natureza, normalmente os dados são analisados por meio de categorias de respostas (como faremos em nosso caso) e que esses dados apresentam ainda alguns traços comuns. No entanto, ainda segundo Delval, os pesquisadores acabam por subestimar as coincidências existentes, atentando-se mais ao que é diferente e específico de cada concepção do que aos traços gerais das explicações infantis.

Dentro desse contexto, o autor deixa claro que são esses traços comuns que comporiam os estágios que os sujeitos vão percorrendo na construção de sua concepção da realidade social. O autor sustenta ainda que "existem concepções de mundo que se aplicam a diferentes domínios e que têm características semelhantes na forma de abordá-los" (DELVAL, 2002, p. 223). Essas semelhanças podem ser delineadas segundo três níveis de compreensão, que possuem as seguintes características:

NÍVEL I - São enquadradas aqui as interpretações com forte caráter anedótico, em que as explicações são baseadas nos aspectos mais visíveis da situação, os observáveis diretamente e que não implicam processos ocultos que necessitam ser inferidos. As relações são vistas como pessoais e os sujeitos parecem não reconhecer a existência de relações propriamente sociais.

NÍVEL II - São incluídas aqui as crenças em que se observa o início de consideração de aspectos não-visíveis da situação, ou seja, os sujeitos começam a evidenciar uma primeira tentativa de levar em conta processos inferidos a partir de informações de que dispõem. Os conflitos são mais claramente percebidos, embora os sujeitos não consigam encontrar soluções satisfatórias pela dificuldade em considerar aceitáveis os diferentes pontos de vista. Nessas explicações, os sujeitos começam a estabelecer a distinção entre as relações pessoais e as institucionalizadas ou sociais.

NÍVEL III - Aqui as explicações rudimentares dos níveis anteriores são substituídas por concepções que consideram os processos ocultos e não-visíveis 
também característicos das relações sociais. Os sujeitos demonstram possuir uma visão mais real do que ocorre ao seu redor, passam a considerar, sistematicamente, as distintas possibilidades presentes em uma situação, a coordenar os diferentes pontos de vista e a refletir sobre diferentes alternativas.

Segundo Delval (2002), o que diferencia um nível do outro não são apenas os princípios explicativos contidos em cada um, mas "a possibilidade de combinar as explicações entre si e estabelecer uma hierarquia entre elas" (DELVAL, 2002, p. 232) ou, melhor dizendo, os níveis não podem ser considerados separadamente a partir de suas características, mas numa evolução de concepções, com uma ordem de sucessão.

Os dados da presente pesquisa foram analisados a partir de categorias de respostas agrupadas nos níveis apresentados anteriormente. Para a quantificação inicial das respostas foi feita análise de frequência e frequência relativa (porcentagem) em cada uma das categorias, de modo a se ter uma visão inicial dos dados e das possíveis diferenças encontradas entre os dois ambientes de ensino. A partir desses primeiros dados, foi aplicado o Teste Qui-Quadrado $\left(\mathrm{c}^{2}\right)$ em cada uma das categorias de respostas, com a finalidade de verificar a relação de dependência entre as variáveis: categoria e ambiente. Adotamos na aplicação de todos os testes o nível de significância (a) igual a 0,05. Dessa forma, valores obtidos de $\mathrm{p}$ menores que 0,05 foram considerados significantes, ou seja, demonstraram haver associação entre ambiente e categoria de resposta analisada. O asterisco colocado na frente de uma categoria, nas tabelas construídas, aponta a associação estatisticamente significante entre aquela categoria e o ambiente escolar, sob o nível de significância de 0,05.

$\mathrm{Na}$ busca de oferecer uma sequência evolutiva das diferentes explicações, optamos, na análise das entrevistas, assim como Cantelli (2000), por uma apresentação dividida por eixos temáticos que permitem uma melhor compreensão do raciocínio dos sujeitos. Os eixos temáticos obtidos por meio da entrevista foram assim definidos:

Primeiro eixo temático - Compreensão do objetivo educacional da escola, referente às questões: "Você acredita ser importante frequentar a escola? Por quê? O que você faz na escola? E isso serve para quê?".

Segundo eixo temático - Preferências na rotina da escola, referente às questões: "O que você mais gosta de fazer na escola? E o que menos gosta?". 
Terceiro eixo temático - Caracterização inicial da escola, referente às questões: "O que é preciso para ser uma escola? Por que é necessário tudo isso?”.

Quarto eixo temático - Concepções de escola boa e escola ruim, referente às questões: "Para você o que é uma escola boa? E uma escola ruim?".

Quinto eixo temático - Objetivo educacional da profissão de professor, referente às questões: "Para você, o que um professor faz? Para que serve um professor?". Sexto eixo temático - Compreensão da necessidade de formação para o exercício da função de professor, referente às questões: "Qualquer pessoa pode ser professor? Como uma pessoa aprende a ser professor?".

Sétimo eixo temático - Concep̧õoes do "bom" e "mau" professor, referente às questões: "Para você, o que seria um 'bom' professor? E um 'mau' professor?".

Oitavo eixo temático - Objetivo do ensino, referente à questão: "Como se deve ensinar?".

Em razão dos limites desse artigo, apresentaremos aqui somente os dados obtidos na entrevista semiestruturada e que dizem respeito às representações sobre escola, especificamente os dados do terceiro e quarto eixos temáticos.

\section{Terceiro eixo temático - Caracterização inicial da escola}

As questões centrais que nortearam a análise deste eixo foram: "O que é preciso para ser uma escola?" "Por que é necessário tudo isso?". É importante salientar que essas questões foram as de mais difícil compreensão pelos entrevistados. Nesse sentido, a categorização das respostas respeitou as primeiras concepções apresentadas pelos sujeitos, sobretudo aquelas que vieram antes da pergunta: "E quando as crianças chegarem nessa escola vai ter alguém lá para receber elas?”, utilizada durante o desenvolvimento da entrevista.

As respostas apresentadas pelos sujeitos foram classificadas em três categorias:

\section{Categoria 1 - Aspectos Materiais}

A categoria "Aspectos materiais" refere-se às respostas em que a caracterização da escola está apoiada em dados externos, diretamente observáveis, tais como: estrutura física (construção do prédio, sala de aula e outros); materiais (de construção, didáticos e outros.); etc., como exemplifica a seguinte resposta: 
ALA (8,2 AT $^{5}$ ) - O que é preciso para se ter uma escola? - Lousa, mesa, cadeira e... gir, material. - Só isso? - Ab!... precisa de tijolo pra construir. - E quando as crianças chegarem nessa escola vai ter alguém lá para receber elas? - Lá vai ter a diretora, as professoras... as professoras... e as tias serventes pra abrir o portão pras crianças entrarem. - E por que é necessário tudo isso? - Porque a escola nunca pode ficar vazia, sem nada.

Categoria 2 - Aspectos Subjetivos

A categoria aspectos subjetivos compõe-se pelas respostas que incluem desejos pessoais, valores e estados emocionais na caracterização da escola. Nessa categoria, observam-se respostas cujas descrições estão apoiadas na necessidade de: "ter bom aluno", "ter boa professora", "não ficar brigando" entre outras. Vejamos alguns exemplos:

LEO (8,0 AT) - O que é preciso para ser uma escola? - Professores, professoras, adulto para separar briga e um diretor. - E por que precisa de todos para ser uma escola? - Pra conseguir controlar tudo, tudo o que a criança tá fazendo.

VIM (7,7 $\left.\mathbf{A S M C}^{\mathbf{8}}\right)$ - O que você acha que é preciso para se ter uma escola? - Ter bom aluno, boa professora, não ficar brigando, levantando, a gente fica obedecendo, quando bate o sinal ir pra fila, ter inspetora, a noite ter cachorros de guarda pra não ser roubada e a gente não ficar sem estudar, não ficar correndo, brigando... é bem legalizinho. - E por que será que a gente precisa de tudo isso? - Pra ser uma escola onde todo mundo vai querer estudar.

Categoria 3 - Aspectos Materiais e Humanos

Essa categoria refere-se às respostas em que os aspectos materiais e humanos estão integrados na caracterização da escola. Alguns exemplos:

YAS (8,0 AT) - O que você acha que é preciso para se ter uma escola? - Tem que ter professoras, alunos, mesa, cadeiras, lápis, borracha, água pra beber e banheiro. E por que será que a gente precisa de tudo isso? - Porque senão a gente vai ficar com vontade de ir no banheiro ou de beber água, ou de escrever e ler.

GBY (7,3 ASMC) - O que você acha que é preciso para se ter uma escola? - Primeiro fica tudo mato, aí depois faz a escola, aí põe as coisas, mesa, cadeira, carteira, armário, depois vêm as professoras, vêm com uns papel e entrega, tem diretor. - E por que será que a gente precisa de tudo isso? - É que tem que ter muita criança e tudo pra elas, não pode faltar senão não aprende. 
A quantificação das respostas por categorias é apresentada na tabela a seguir, considerando o ambiente escolar pesquisado.

TABELA 1: Distribuição de frequência e frequência relativa da caracterização inicial da escola segundo 0 ambiente escolar pesquisado.

\begin{tabular}{|c|c|c|c|c|}
\hline \multirow{4}{*}{$\begin{array}{c}\text { Eixo Temático: } \\
\text { Caracterização inicial da escola } \\
\text { Nível } ~^{10}\end{array}$} & \multicolumn{4}{|c|}{ Ambientes } \\
\hline & \multicolumn{2}{|c|}{ Tradicional } & \multicolumn{2}{|c|}{ Sócio-Moral Construtivista } \\
\hline & $f^{8}$ & $\%^{9}$ & $f$ & $\%$ \\
\hline & & & & \\
\hline 1-Aspectos materiais* & 23 & $77 \%$ & 9 & $41 \%$ \\
\hline 2-Aspectos subjetivos & 1 & $3 \%$ & 1 & $5 \%$ \\
\hline 3-Aspectos materiais e humanos ${ }^{*}$ & 6 & $20 \%$ & 12 & $55 \%$ \\
\hline
\end{tabular}

O Teste Qui-Quadrado efetuado na categoria "Aspectos materiais" apontou uma relação bastante significativa $(\mathrm{p}<\mathrm{a})$ entre ambiente e a percepção de que são necessários somente aspectos materiais (aparentes, concretos) para a constituição de uma escola. A maioria dos alunos inseridos no ambiente tradicional tende a considerar como suficiente a presença de aspectos materiais para se ter uma escola, ao passo que a maioria dos alunos do ambiente sócio-moral construtivista tende a considerar que isso não é suficiente, indicando a necessidade de outros elementos.

A partir da aplicação do Teste Qui-Quadrado para a categoria "Aspectos materiais e humanos" e ambiente escolar foram obtidos resultados estatisticamente significantes $(p<a)$, apontando assim uma relação significativa entre o ambiente e a percepção da necessidade de aspectos materiais e humanos. Entre os alunos inseridos no ambiente sócio-moral construtivista, há tendência maior a indicar a presença de aspectos materiais e humanos para a caracterização de uma escola. Uma baixa porcentagem dos alunos do ambiente tradicional apresenta tal percepção. 
Quarto eixo temático - Concepcões de escola boa e escola ruim

As questões centrais que nortearam a análise deste eixo foram: "Para você, o que é uma escola boa? E uma escola ruim?". Foram encontradas cinco categorias:

Categoria 1 - Baseadas em bens materiais

Alguns sujeitos explicaram a diferença entre a escola boa e a escola ruim pautados pelos bens materiais que a instituição poderia ter ou não, como "ter mesa", "ter cadeira", "ter computador". Alguns exemplos:

LUI (7,4 AT) - Como você acha que é uma escola boa? - Tem muitos negócios e bastante coisa pra fazer... tem cadeira, carteira, computador, Internet. Só!. - E como seria uma escola ruim? - Não tem computador, não tem nada.

TAU (7,4 ASMC) - Para você o que seria uma escola boa? - Tem de tudo o que as crianças gostam... Brinquedos, quadra. - E como seria uma escola ruim? - Não tem brinquedo e não tem quadra.

Categoria 2 - Assistencialismo

As respostas encontradas nesta categoria dizem respeito às explicações para a escola boa e ruim baseadas em ações assistencialistas, como: "dá leite", "dá comida", "dá dinheiro", entre outras respostas, como podemos ver a seguir:

GAA (7,8 AT) - Para você, o que seria uma escola boa? [...] que dá comida pra gente não ficar com fome.

LUM (8,7 ASMC) - Para você, o que seria uma escola boa? - Porque tem comida. - E como seria uma escola ruim? - É que não tem comida.

Categoria 3 - Aspectos subjetivos e referentes a comportamentos considerados adequados.

Esta categoria apresenta as respostas em que predominam aspectos subjetivos e referentes ao comportamento das pessoas da escola, tais como valores, bondade das pessoas, limpeza: "as pessoas não brigam", "tem professora boazinha", "é limpa" entre outros. Exemplos:

IGO (7,9 AT) - Para você, o que é uma escola boa? - Que tem pessoas boas, professoras boas, alunos bons [...]. - E a escola ruim? - Que tem professoras ruins que só ficam batendo no armário. 
PED (8,1 ASMC) - Para você, o que seria uma escola boa? - A escola que gente não briga, que não bate, que não belisca. - E como seria uma escola ruim? - Que briga, que derruba no chão, machuca.

Categoria 4 - Ensino - aprendizagem

Segundo estes sujeitos, a diferença entre uma escola boa e uma escola ruim estaria diretamente ligada à aprendizagem de conteúdos escolares. Entre as justificativas estão: "aprende bastante", "que ensina a ler e escrever" entre outras. É o caso de:

ALL (7,5 AT) - Para você, o que é uma escola boa? - A escola boa é que ensina bem. - E a escola ruim? Como ela é? - É que a gente não ensina nada.

YME (7,8 ASMC) - Para você, como seria uma escola boa? - Que faz a gente aprender a ler e escrever. - E como seria uma escola ruim? - Quando as professoras não faz a gente ler e nem escrever.

A quantificação das respostas por categorias é apresentada na tabela a seguir, considerando o ambiente escolar pesquisado.

TABELA 2: Distribuição de frequência e frequência relativa da concepção de escola boa e escola ruim segundo o ambiente escolar pesquisado.

\begin{tabular}{c|cccc} 
& \multicolumn{4}{|c}{ Ambientes } \\
Eixo Temático: & \multicolumn{3}{|c}{ Tradicional } & Sócio-Moral Construtivista \\
\hline Concepção de escola boa e escola ruim & $\mathrm{f}$ & $\%$ & $\mathrm{f}$ & $\%$ \\
Nível I & & & & \\
1-Baseadas em bens materiais & 11 & $37 \%$ & 4 & $18 \%$ \\
2-Assistencialismo & 2 & $7 \%$ & 1 & $5 \%$ \\
3-Aspectos subjetivos e referentes a & 13 & $43 \%$ & 17 & $77 \%$ \\
comportamentos considerados adequados & & & & \\
$\quad$ Nível II & 3 & $10 \%$ & 3 & $14 \%$ \\
4-Ensino- Aprendizagem & 3 & $13 \%$ & 0 & $0 \%$ \\
5-Não respondeu/não sabe/outras & & & & \\
& & & &
\end{tabular}

Em 5: ${ }^{2}=4.68 ; g l=1 ; p=0.031$

O Teste Qui-Quadrado aplicado na categoria "Aspectos subjetivos e referentes a comportamentos considerados adequados" apontou uma relação significativa $(\mathrm{p}<\mathrm{a})$ entre ambiente escolar e a consideração 
de aspectos subjetivos para caracterização de uma boa escola. Os alunos inseridos no ambiente sócio-moral construtivista tendem a indicar mais os aspectos subjetivos e referentes a comportamentos considerados adequados para a caracterização de uma boa escola, ao passo que essa tendência é bem menos observada entre os alunos do ambiente tradicional.

\section{Discussão}

A análise qualitativa da entrevista nos apresenta dados que evidenciam as ideias bastante peculiares que as crianças constroem acerca da realidade social, no caso do tema do presente artigo, sobre a escola. $\mathrm{Na}$ análise dos dados conseguidos a partir da entrevista, as respostas dos sujeitos de ambos os ambientes se assemelharam na maneira como viam a escola e por não possuírem ainda uma real compreensão do objetivo educacional da instituição escolar.

Em suas respostas, nossos sujeitos lançaram mão de explicações centradas nos aspectos mais aparentes e concretos desse tipo de conhecimento. Tal fato nos remete às características do nível I de compreensão dos fenômenos sociais, no qual há predomínio da visão daquilo que é percebido diretamente, considerando-se somente aspectos parciais para as explicações. A maioria dos nossos sujeitos encontrava-se no nível I de compreensão da realidade social e, embora a análise qualitativa não tenha evidenciado grande diferença entre os ambientes, a análise estatística simples e a aplicação do Teste Qui-Quadrado nos permitem fazer alguns apontamentos importantes.

No terceiro eixo temático, em que buscamos conhecer o que as crianças consideravam necessário para se ter uma escola, encontrou-se diferença significativa entre os ambientes em duas das categorias de respostas. A primeira diferença evidenciada foi na categoria 1 "Aspectos materiais", que teve como explicações aspectos referentes a objetos, construções entre outras; nessa categoria, a maioria das respostas era proveniente de crianças pertencentes ao ambiente escolar tradicional.

Já na categoria 3, "Aspectos materiais e humanos", ocorreu o contrário: a maioria das respostas era proveniente de crianças pertencentes ao ambiente escolar sócio-moral construtivista. Tais respostas 
destacaram também, além dos aspectos materiais, a necessidade de professores, cozinheiras, diretor, entre outras pessoas, para a existência de uma escola. Nesse eixo temático, podemos inferir que, de certa forma, as respostas das crianças inseridas em ambiente cooperativo são mais evoluídas do que as do outro ambiente, já que se utilizam de mais elementos na constituição de suas explicações.

Mesmo que ambas as categorias estejam inseridas no nível I de compreensão, consideramos que a categoria 3 seria constituída por explicações mais elaboradas, já que não se centra apenas nos aspectos materiais ou concretos, mas leva em consideração a necessidade de alguns sujeitos sociais no interior de uma escola para que ela exista.

Em seguida, no quarto eixo temático, em que buscamos conhecer como as crianças concebiam uma escola boa e uma escola ruim, o teste destacou diferenças significativas na categoria 3, "Aspectos subjetivos e referentes a comportamentos considerados adequados". Nessa categoria, a maioria das respostas explicava os tipos de escola existentes baseada em atitudes das pessoas que ali trabalham, consideradas adequadas ou não. Essas respostas eram, em sua maioria, provenientes de crianças pertencentes ao ambiente cooperativo.

É claro que, muitas vezes, essas atitudes que as crianças afirmam considerar adequadas podem ser uma reprodução daquilo que o adulto considera adequado, isto é, ser algo na visão do adulto e não dos pequenos. Torna-se difícil distinguir o que é da real compreensão da criança e o que é apenas reprodução do que os adultos dizem, como explica Piaget:

(...) as regras morais, que as crianças aprendem a respeitar, lhe são transmitidas pela maioria dos adultos, isto é, ela as recebe já elaboradas, e, quase sempre, nunca elaboradas na medida de suas necessidades e de seu interesse, mas de uma vez só pela sucessão ininterrupta das gerações adultas anteriores. (PIAGET, 1994, p. 23)

O objetivo do presente trabalho não é analisar como as crianças concebem as regras da sala, tampouco as normas de convivência da escola. Todavia, se acreditarmos que, ao falarem sobre condutas consideradas adequadas ou não, essas crianças estejam repetindo as imposições dos adultos, poderíamos então perguntar: por que os alunos do ambiente tradicional não fazem o mesmo, tendo em vista que as 
coerções, as imposições, as normas eram muito mais rígidas e repetidas nessa sala? Tal fato sugere que as crianças do ambiente sócio-moral construtivista estejam discutindo mais essas questões e, por isso mesmo, tais ideias apareçam mais em suas respostas.

Esses fatos, somados à análise dos outros eixos temáticos e dos demais instrumentos utilizados na pesquisa, a nosso ver, confirmam nossa hipótese, isto é, o ambiente influencia o desenvolvimento dos alunos, assim como já salientaram Delval (1993), Devries e Zan (1998), Araújo (1996) e Vinha (2000).

No entanto, em relação à construção do conhecimento social, especificamente sobre o tema pesquisado, as representações sobre escola, não houve grande diferença entre os ambientes. Tal fato nos faz inferir que se o assunto/tema não for trabalhado em sala de aula, não podemos pensar que as crianças estejam elaborando concepções mais avançadas sozinhas, razão pela qual a maioria das respostas encontrava-se no nível I nos dois ambientes. Todavia, a pequena diferença existente, ainda que no mesmo nível de compreensão da realidade social, já é um indicativo de que estar num ambiente em que as próprias concepções sejam respeitadas e as discussões e trocas sejam valorizadas permite aos pequenos transformar, aos poucos, as concepções sobre a realidade que os cerca.

Destacamos ainda que as noções sociais devem ser exploradas em sala de aula, como mostram as pesquisas de Borges (2001) e Saravali (1999), mas que devem sempre caminhar em prol dos processos percorridos pelas crianças.

Um trabalho que leve em consideração o desenvolvimento infantil deve ter como foco principal a criança e esta necessita ser vista como um sujeito ativo e capaz de construir suas próprias noções. O professor deve diminuir ao máximo seu poder de tomada de decisões pela criança e mudar a postura de único detentor do conhecimento em sala. Esse docente precisa estar apto a propor desafios, desequilibrando a criança sempre que ela mostrar condições de poder avançar. E isso deve ocorrer em relação a todos os tipos de conhecimento, inclusive o conhecimento social. 


\section{Considerações finais}

O objetivo central do nosso estudo era comparar as representações de escola e de professor em crianças da primeira série inseridas em ambientes educacionais distintos. Trouxemos para reflexão no presente artigo alguns dos dados obtidos a partir da aplicação de um questionário a respeito das ideias referentes à escola.

Nossos dados mostraram, em concordância com as pesquisas referentes ao conhecimento social, que as crianças percorrem caminhos bastante singulares na construção de suas representações sobre a escola. Isso significa que, mesmo em se tratando de um conhecimento que, para muitos, assume um caráter de transmissão cultural ou pedagógica, os sujeitos não o assimilam de forma passiva, mas o reelaboram e o interpretam.

As ideias apresentadas por nossos sujeitos concentraram-se em explicações baseadas nos aspectos mais visíveis da situação, sem a existência de processos ocultos que necessitam ser inferidos. Os dados chamam a atenção para o fato de que as crianças estão construindo suas próprias ideias sobre um tema que lhes é tão familiar e rotineiro como a instituição escolar. Assim, organizam as informações que recebem, provenientes, por exemplo, das verbalizações dos docentes, unindo-as e inserindo-as em seus próprios processos e sistemas, transformando-as assim em concepções bastante singulares. Afinal, ninguém ensina para uma criança que para se ter uma escola é preciso não ficar brigando e obedecer, ou mesmo que uma escola boa é aquela em que as pessoas não brigam. Entretanto, tais ideias aparecem nesta pesquisa.

Nossa hipótese inicial foi a de que uma criança inserida em um ambiente permeado por relações horizontais de cooperação entre professor e aluno, bem como entre aluno e aluno, apresentaria ideias diferenciadas acerca do tema que pesquisávamos, como também maior tendência à reflexão. Como no ambiente tradicional essas relações não são valorizadas da mesma forma e a reprodução, constantemente solicitada e imposta, gera a passividade por parte do educando, acreditávamos que as respostas e reflexões seriam diferentes.

No instrumento analisado aqui, observamos a existência de diferenças entre as respostas dos sujeitos inseridos nos dois ambientes educativos, ainda que pequenas. Tal fato confirmou nossa hipótese inicial, 
mostrando que a organização didática e a postura do professor trazem benefícios para as crianças, no que diz respeito ao seu desenvolvimento social, moral e também cognitivo.

Todavia, a não-existência de diferenças maiores nos faz inferir que, mesmo que o ambiente favoreça o desenvolvimento infantil em vários aspectos, em relação ao conhecimento social é necessário o trabalho direcionado a determinado tema que se quer explorar. Portanto, cabe aos docentes conhecerem as concepções que as crianças elaboram sobre as noções sociais e, a partir daí, dirigir as futuras ações e o trabalho pedagógico. Dessa forma, as ações em sala de aula podem favorecer ou não a consolidação e o sucesso da construção desse tipo de conhecimento.

Portanto, o trabalho com o conhecimento social necessita ser levado para a sala de aula de tal forma que as crianças possam pensar, compreender, debater, formular e reformular suas próprias ideias. Isso exige do professor certas modificações de procedimentos que demandam, por sua vez, mudança nas concepções pedagógicas e epistemológicas. Parece-nos que o ambiente cooperativo, mais próximo de uma proposta construtivista para a educação, está mais preparado para fazer isso.

A necessária interação, possibilitada pelo docente e estabelecida pela criança, tem influência na forma como se processam o desenvolvimento físico, social, afetivo, moral e intelectual dos alunos. No caso do tema tratado no presente trabalho, essa influência ocorre na abertura de possibilidades para que os alunos tenham a compreensão da real função da escola.

A partir de nossa pesquisa, acreditamos poder contribuir para a compreensão de como se dá a construção do conhecimento da criança acerca da realidade social, especificamente sua compreensão de escola. Nosso estudo e os dados obtidos trazem contribuições para as reflexões e demais investigações sobre a construção do conhecimento social pela criança e sobre as implicações dessa construção para o trabalho docente. 


\section{Referências}

ARAUJO, U. F. O ambiente escolar e o desenvolvimento do juízo moral infantil. In: MACEDO,L. (Org.) Cinco estudos de educação moral. São Paulo: Casa do Psicólogo, 1996. p. 105-136.

ASSIS, O. Z. M. Conhecimento físico, conhecimento lógico-matemático e conhecimento social. In: ASSIS, Mucio; ASSIS, Orly (Org.) PROEPRE: Fundamentos Teóricos e prática pedagógica para a educação infantil. Campinas: Faculdade de Educação, Unicamp, 2003. p. 78-104.

BORGES, R. R. A construção da noção de família em crianças pré-escolares Dissertação (Mestrado em educação) Universidade Estadual de Campinas, Faculdade de Educação, 2001.

CANTELLI, V. C. B. Um estudo psicogenético sobre as representações de escola em crianças e adolescentes. Dissertação (Mestrado em educação) Universidade Estadual de Campinas, Faculdade de Educação, 2000.

CHAVES, M.A.; BARBOSA, M.F. Representações sociais de crianças acerca da sua realidade escolar. In: Estudos de psicologia, São Paulo, v.15, n. 3, p. 29-40, 1998.

CRUZ, S.H.V. A representação da escola em crianças da classe trabalhadora. Dissertação (Mestrado em Psicologia) IP, Universidade de São Paulo, São Paulo, 1987. 2v.

DELVAL, J. La construción espontánea de las nociones sociales y su enseñanza. In: HUARTE, F. (Coord.) Temas actuales sobre psicopedagogía y didáctica. Madrid: Narcea/ II Congresso Mundial Vasco, 1988.

DELVAL, J La representacion infantil del mundo social In: TURIEL, E., ENESCO, I. y LINAZA, J. (Comps.). El mundo social em la mente del nino. Madrid: Alianza, 1989.

DELVAL, J. La construcción del conocimiento social. 1990. (mimeo)

DELVAL, J; ECHEITA, G. La compreensión en el niño del mecanismo de intercambio económico y el problema de la ganancia. In: Infancia y aprendizage, Madrid, 1991, n. 54, p. 71-99.

DELVAL, J. El constructivismo y la adquisición del conocimiento social. In: Apuntes de Psicología, Madrid, n. 36, p. 5-24, 1992.

DELVAL, J. La construción del conocimiento social. In: Primer Encuentro Educar. 1993 (mimeo).

DELVAL, J. Introdução à prática do Método Clínico - descobrindo o pensamento das crianças. Trad. Fátima Murad. Porto Alegre: Artmed, 2002.

DENEGRI, M. A construção do conhecimento social na infância e a representação da pobreza e desigualdade social: desafios para a ação educativa. In: $V$ Encuentro Educar. 1998. (mimeo)

DEVRIES, R.; ZAN, B. A ética na educação infantil: o ambiente sócio-moral na escola. Porto Alegre: Artmed, 1998.

ENESCO, I. et al. La comprensión de la organización social em niños y adolescentes._Madrid: CIDE, 1995.

ENESCO, I. A representação do mundo social na infância, 1996. (mimeo)

GODOY, E. A. de A representação étnica por crianças pré-escolares: um estudo de caso a luz da teoria piagetiana. Dissertação (mestrado em educação) Faculdade de Educação da UNICAMP, Campinas, 1996.

GONÇALVES, M.F.C. Se a professora me visse voando ia me por de castigo. Dissertação 
(Mestrado em educação) Faculdade de Educação da Unicamp, Campinas, 1990.

KAMII, C. A criança e o número: implicações educacionais da teoria de Piaget para a atuação junto a escolas de 4 a 6 anos. Trad. Regina A. de Assis, 21 ed. Campinas, SP: Papirus, 1996.

KAMII, C.; DEVRIES, R. O conbecimento físico na educaşão pré-escolar-implicações da teoria de Piaget. Trad. Maria Cristina Goulart. Porto Alegre: Artmed, 1991.

NAVARRO, A.; PEÑARANDA, A. Qué es um rico? Y un pobre?: un estudio evolutivo con niños mexicanos y españoles. In: Infancia y Aprendizaje, Madrid, n. 13, v. 1, p. 67-80, 1998.

PIAGET, J. A epistemologia genética, sabedoria e ilusões da filosofia, problemas de epistemologia genética. São Paulo: Abril Cultural, 1978. (Col. Os Pensadores)

PIAGET, J. O juízo moral na criança. São Paulo: Summus, 1994.

PIAGET, J. Psicologia e pedagogia. Trad. Dirceu Accioly Lindoso e Rosa Maria Ribeiro da Silva) . 9 ed. Rio de Janeiro: Forense Universitária, 1998.

SARAVALI, E.G. As idéias das crianças sobre seus direitos: a construção do conhecimento social numa perspectiva piagetiana. Dissertação (Mestrado em Educação). Faculdade de Educação da Unicamp, Campinas. 1999.

SIERRA, P.; ENESCO, I. la compresiòn del acceso a distintas profesiones: un estúdio evolutivo. In: Infancia e aprendizaje, Madrid, 1993.

TORTELLA, J.C.B. Amizade no contexto escolar. Dissertação (Mestrado em educação). Faculdade de Educação da Unicamp, Campinas, 1996.

TORTELLA, J.C.B. A representação de amiz̧ade em díades de amigos e não amigos. Dissertação (Doutorado em educação). Faculdade de Educação da Unicamp, Campinas, 2001.

VINHA, T.P. O educador e a moralidade infantil: uma visão construtivista. São Paulo: Mercado de Letras, 2000.

\section{Notas}

1 Financiada pela Fundação de Amparo à Pesquisa do Estado de São Paulo - FAPESP.

2 A título de complementação: dois processos-chaves da obra piagetiana são assimilação e acomodação. Segundo Piaget, a assimilação é entendida "como a acepção ampla de uma integração de elementos novos em estruturas ou esquemas já existentes”, ou seja, por um lado implicaria a noção da significação e, por outro, expressaria a ideia de que todo conhecimento está ligado à ação e de que o conhecimento de um objeto ou acontecimento seria o mesmo que assimilá-lo a esquemas de ação (PIAGET, 1978, p. 11). Já o processo de acomodação é definido como "toda modificação dos esquemas de assimilação, por influência de situações exteriores”, como, por exemplo, quando um esquema não é suficiente para responder a uma situação, surge a necessidade de o esquema modificar-se em função da situação (PIAGET, 1978, p. 11). Esses processos internos são mecanismos inseparáveis e complementares que, ao atingirem equilíbrio entre si, resultam em adaptação.

3 No presente artigo, trataremos apenas das representações sobre a escola.

4 Idem nota 3. 
5 As questões 2, 4 e 7 foram extraídas da pesquisa de Cantelli (2000).

6 Ambiente Tradicional.

7 Ambiente Sócio-Moral Construtivista.

8 Cabe destacar que a frequência de respostas não corresponderá ao total de sujeitos da pesquisa, já que um mesmo sujeito poderá fornecer, em uma resposta, explicações decorrentes de uma ou mais categorias diferentes.

9 O cálculo percentual foi baseado no total de sujeitos de cada ambiente: Ambiente Tradicional (30) e Ambiente Sócio Moral Construtivista (22).

10 As categorias foram dispostas de forma crescente em relação à evolução das noções de escola, considerando-se os níveis de evolução da compreensão da realidade social apresentados por Delval (2002).

11 A categoria "Não respondeu/ não sabe/ outros" não pode ser enquadrada em um nível de compreensão dos sujeitos, dessa forma é importante ressaltar que não se torna parte do nível II, encontrando-se ali devido à disposição da Tabela.

Recebido: $24 / 01 / 09$

Aprovado: 20/08/09

Contato:

Universidade Estadual Paulista Júlio de Mesquita Filho Faculdade de Filosofia e Ciências

Campus de Marília

Departamento de Psicologia da Educação

Av. Hygino Muzzi Filho, 737

Campus Universitário

CEP 17525-900

Marília/SP 